\title{
Certified reference materials of trace elements in water
}

\author{
A K Agrawal \\ National Physical Laboratory, Dr K S Krishnan Marg, New Delhi 110 012, India
}

\begin{abstract}
Measurement of trace elements is playing a vital role in industries and various sectors of science and technology including semiconductors, food, health and environmental sectors. In most of the cases a small error in measurement can vitiate all the measures taken for quality control and management. Many decisions regarding the suitability of material/products are based on the analysis. To reduce or eliminate the rejection rate of the products, accurate and reliable measurements are needed which can be achieved by the use of certified reference materials (CRMs). Their use in calibration of analytical equipments and validation of test methods ensures high quality in measurements and it provides traceability to the measurement data with national/international measurement systems (SI unit) also. In the present scenario of globalization of economy, use of certified reference materials (CRMs) in measurements is essential for global acceptance of products and test reports. Their use fulfil a mandatory requirement of international quality systems (ISO 9000, ISO/IEC standard 17025) including our national accreditation body, National Accreditation Board for Testing and Calibration Laboratories (NABL), World Trade Organization (WTO) etc. International manufacturers of CRMs are meeting most of the requirement of CRMs of the country. To meet the demand of CRMs indigenously, the National Physical Laboratory, India initiated a national programme on preparation and dissemination of certified reference materials.
\end{abstract}

Keywords. CRMs; traceability; accreditation; water.

\section{Introduction}

National/international standards writing organizations had laid down the products specifications to specify the quality of the products and guidelines suitable for various usages. To find the suitability of the products their precise characterization is necessary and it can be achieved by the use of CRMs in quality control of measurement by calibration of analytical equipment and validation of test methods. It enhances the quality of measurements and provides traceability to the national and international measurement systems. It is a mandatory requirement of all the national/ international accreditation bodies and World Trade Organization (WTO) for global acceptance of test/calibration report and global trade (ISO/IEC 17025-1999). The definitions of reference materials and certified reference materials as given by International Standards Organization are universally accepted (ISO Guide 30, 1992).

A large number of CRMs are required in the country for quality management in all the sectors of science and technology including accredited laboratories in accordance to the ISO and WTO requirements. In most of the cases the maximum permissible limits of elements is at very low level. For trace analysis, CRMs of mono and multi-elemental solutions are being preferred and used extensively in quality control and management. Therefore, the CRMs of elemental solution in low concentration are

aka@mail.nplindia.ernet.in required for calibration of analytical equipment and validation of test methods. Most of the CRM producers are marketing the CRMs of elemental solution in higher range of concentration i.e. $1,000-10,000 \mathrm{mg} / \mathrm{l}$. Analysts have to dilute them in many folds for calibration of the equipment for use at trace level testing which causes error in measurements. To minimize the error due to dilution of the CRMs of concentrated elemental solution, NPL initiated a programme on preparation of the CRMs of elemental solutions in the lower concentration range in accordance to the requirement of the measurement under its ongoing major collaborative programme on planning, preparation and dissemination of CRMs. National Physical Laboratory is coordinating this national programme to meet the requirement of CRMs in the country indigenously. It created a network of thirty top ranking laboratories of the country including nineteen CSIR laboratories. Names and addresses of participating laboratories are given in table 1 .

\section{Preparation of CRMs of elemental solutions}

Certified reference materials of elemental solutions have been prepared by dissolution of high purity metals/salts in ultra-pure acids and water. Ultra-pure water and acids have been prepared in the laboratory by using sub-boil distillation technique (Gupta et al 2002). After sub-boil distillation concentration of the trace elements in water and acids reduced to be $<1$ part per billion for most of the elements hence, their use in preparation of CRMs of 
elemental solution minimizes the contribution of solvents (Balaram et al 2000).

Stock solutions of $1000 \mathrm{ppm}$ of mono-elemental solutions have been prepared initially. Simultaneously, 101 solutions of the mono and multi-elemental solutions have been prepared by further dilution in appropriate quantities with $1 \%$ solution of acid in ultra-pure water to get the required concentration of the BNDs (Gupta et al 1989, 1993; Agrawal and Kishan Lal 2001; Agrawal et al 2003). Similarly multi-elemental solutions have been prepared by mixing of the stock solutions of monoelemental solutions. These solutions were stored in ultra cleaned 'TARSONS' brand polythene bottles (Moody and Lindstrom 1977).

\section{Round robin testing for certification}

Seventeen reputed laboratories of the country are participating in round robin testing for the programme on preparation of CRMs of elemental solutions. Mono and multi elemental solutions prepared under this programme have been sent to these laboratories for measurement of concentration after the study of their homogeneity and stability. All the participating laboratories are free to select any method or technique/s for measurement. For example, concentrations of cations had been measured by using ICP-mass spectrometer or ICP-emission spectrometer or DCP-emission spectrometer or atomic absorption spectrometers (flame and graphite) or ion selective electrodes or UV-visible spectrometers etc. Similarly, anions had been analysed by using ion chromatographs or ion selective electrodes or UV-visible spectrometers etc. Each participating laboratory has to carry out the measurements in replicate at a suitable time interval, preferably a fortnight over a period of six months on 10 different days for statistical computation.

In a typical example mono elemental solution of manganese (BND 1901) had been sent to seventeen laboratories for measurement of its concentration. Fourteen laboratories carried out the measurements and sent the measurement reports. One laboratory measured the samples by two different techniques, hence two code nos. 1a and 1b assigned to it. Mean value of the data along with its spread for all the laboratories is plotted and shown in figure 1. This gives the broad idea about the quality of the data in terms of the spread of the values and comparative values.

Table 1. Laboratories participating in programme on preparation and dissemination of CRMs.






\section{Assignment of certified values}

Data received from the fourteen participating laboratories have been evaluated quantitatively for their quality to identify the outlier laboratories for assignment of certified values. To evaluate the quality of the data quantitatively two types of Z-score values have to be calculated. These are $\mathrm{Z}$-score within the laboratory $\left(\mathrm{Z}_{\mathrm{wi}}\right)$ and $\mathrm{Z}$-score between the laboratories $\left(\mathrm{Z}_{\mathrm{bi}}\right)$. Values of the $\mathrm{Z}$-scores have been calculated by integration of the seven summary statistics-number of the laboratories, median, normalized interquartile range (IQR), robust coefficient of variation $(\mathrm{CV})$, minimum, maximum and range (New Statistics to NATA's Proficiency Programmes 1997). Z-score within the laboratory indicates the variance in the data produced in the laboratory itself and Z-score between the laboratories indicates the variance in the data (median value) produced at different participating laboratories. The quality of the measurement increases with the decrease in the value of $\mathrm{Z}$-score. The value of the $\mathrm{Z}$-score to identify the outlier laboratories may be selected preferably up to 1 , but it should not be greater than 2 in any case. The data of outlier laboratories should be eliminated from the final computation to evaluate the certified value. For example, the values of both the Z-scores i.e. within the laboratory and between the laboratories for manganese solution BND 1901 had been calculated and shown in table 2 and plotted in graphic mode as shown in figures 2 and 3 .

In this case the cut-off value of the Z-score is selected as $\geq 1.5$ to identify the outlier laboratories. Figure 2 shows that the laboratory nos 7 and 11 are having greater variance in the data produced by them and are outlier laboratories for exceeding the fixed value of the Z-score. Similarly laboratory nos 7, 8, 9 and 11 are outliers when median value of individual laboratory is compared with the median value of all the participating laboratories as shown in figure 3 . Finally, the data of four laboratories viz. 7, 8, 9 and 11 does not qualify for inclusion in the statistical calculations to assign the value of concentration of manganese in the solution. The values of the concentration of manganese solution had been calculated as per guidelines of International Standards Organization (ISO Guide 35, 1989). Uncertainty in measurement had also been evaluated at $95 \%$ confidence level $(K=2)$ as per EUROCHEM/CITAC guidelines (Guidelines for Estimation and Statement of Overall Uncertainty in Measurement Results 1996; EURACHEM/CITAC Guide 2000). The value of the concentration of manganese solution has been assigned as $1.00 \pm 0.02 \mathrm{mg} / \mathrm{l}$ at $95 \%$ confidence level. Similarly the certified values and uncertainty in measurement for other CRMs of elemental solutions had also been calculated and their details are given in table 3 .

\section{Future programme}

Following CRMs of elemental solutions are under preparation under this network programme and likely to be released by the end of this year.

(I) Mono elemental solutions: (i) Magnesium, (ii) cobalt, (iii) barium and (iv) strontium.

(II) Multi elemental solutions: (i) Aluminium, arsenic, barium, boron, cadmium, chromium, cobalt, copper, iron, lead, manganese, magnesium, selenium, strontium, vanadium and (ii) fluoride, chloride, sulphate, phosphate and nitrate.

\section{Traceability}

Acceptability of the assigned/certified value of CRM at international level is an important factor. Presently, international measurement system viz. Consultative Committee on Amount of Substance (CCQM) is accepting the values assigned by National Metrology Institute (NMI) of

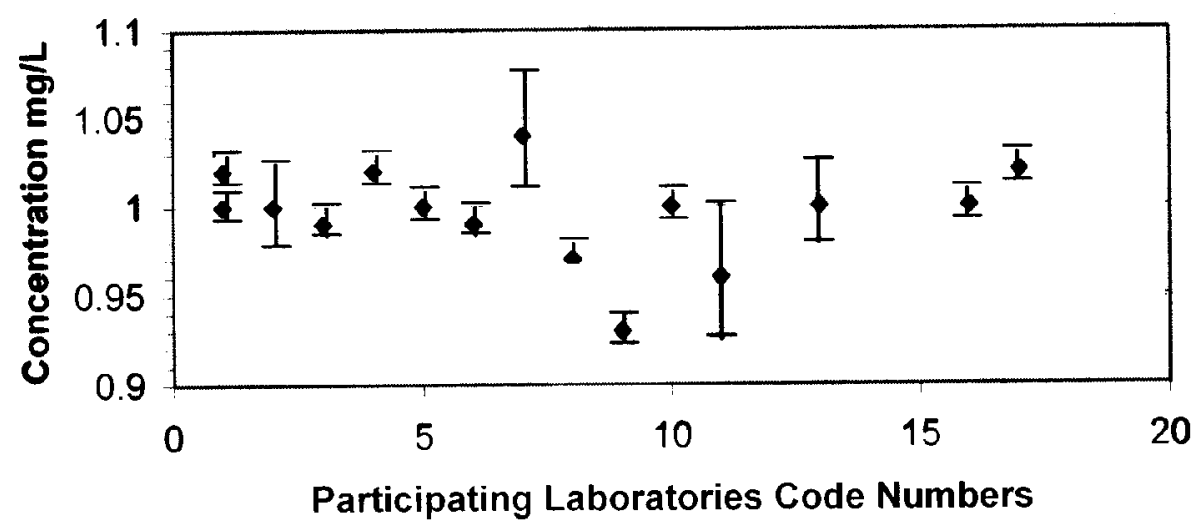

Figure 1. Mean value and spread of the data of manganese solution received from the participating laboratories. 
Table 2. Values of the $\mathrm{Z}$-scores for certified reference material of manganese solution (BND 1901).

\begin{tabular}{|c|c|c|c|}
\hline $\begin{array}{l}\text { Laboratory } \\
\text { code number }\end{array}$ & $\begin{array}{c}\text { Range of } \\
\text { measurement value }\end{array}$ & $\begin{array}{l}\text { Z-score within } \\
\text { the laboratory }\end{array}$ & $\begin{array}{l}\text { Z-score between } \\
\text { the laboratories }\end{array}$ \\
\hline 1a. & $1 \cdot 01-1 \cdot 03$ & $0 \cdot 000$ & $1 \cdot 349$ \\
\hline $1 \mathrm{~b}$. & $0 \cdot 99-1 \cdot 01$ & $1 \cdot 349$ & 0.000 \\
\hline 2. & $0 \cdot 98-1 \cdot 02$ & -0.674 & 0.000 \\
\hline 3. & $0.98-1.00$ & $1 \cdot 349$ & -0.674 \\
\hline 4. & $1 \cdot 01-1.03$ & 0.000 & $1 \cdot 349$ \\
\hline 5. & $0.99-1.01$ & $1 \cdot 349$ & 0.000 \\
\hline 6. & $0.98-1.00$ & 0.000 & -0.674 \\
\hline 7. & $1.01-1.07$ & $2 \cdot 698$ & $2 \cdot 698$ \\
\hline 8. & $0.96-0.98$ & $0 \cdot 000$ & $-2 \cdot 023$ \\
\hline 9. & $0.92-0.94$ & $1 \cdot 349$ & $-4 \cdot 721$ \\
\hline 10. & $0 \cdot 99-1 \cdot 01$ & $0 \cdot 000$ & $0 \cdot 000$ \\
\hline 11. & $0.92-1.00$ & $3 \cdot 372$ & -2.698 \\
\hline 12. & Not measured & & \\
\hline 13. & $0.98-1 \cdot 01$ & -0.674 & 0.000 \\
\hline 14. & Not measured & & \\
\hline 15. & Not measured & & \\
\hline 16. & $0 \cdot 99-1 \cdot 01$ & $1 \cdot 349$ & 0.000 \\
\hline 17. & $1 \cdot 01-1 \cdot 03$ & 0.000 & $1 \cdot 349$ \\
\hline
\end{tabular}

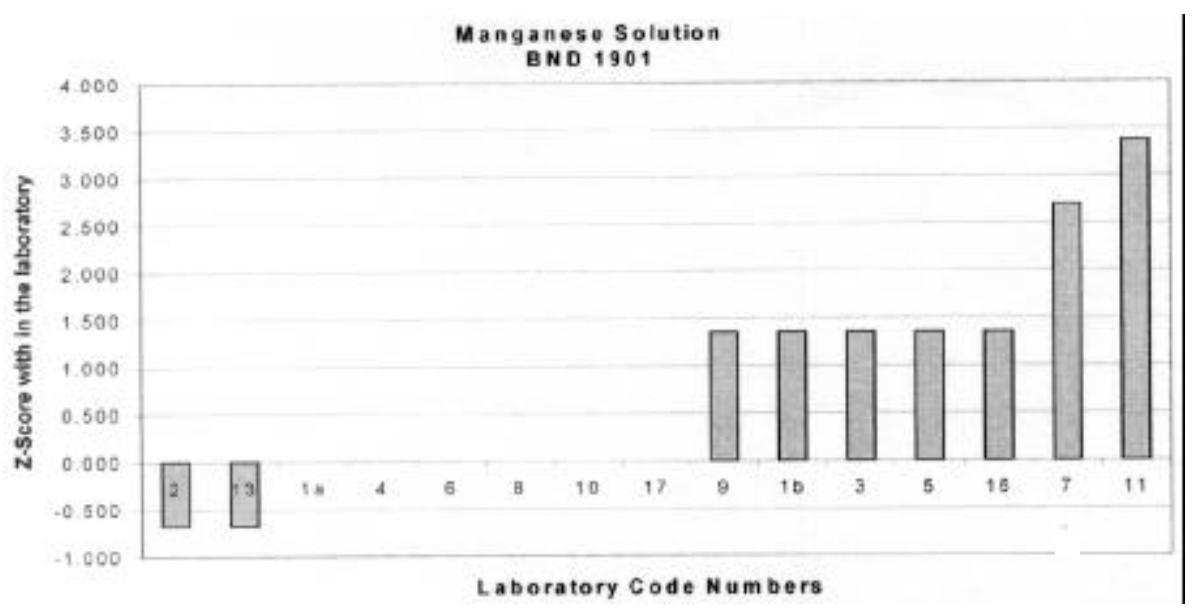

Figure 2. Z-score within the laboratory.

any country. But they have to demonstrate their measurement capabilities by participation in international key comparison programme on measurement in due course. NPLI is continuously participating in international comparison programmes to demonstrate its measurement capability to provide the traceability and acceptability of CRMs developed under this programme. These intercomparison programmes are being organized by various international organizations viz. National Institute of Standards and Technology (NIST), National Association of Testing Authorities (NATA), Institute of Reference Materials and Measurement (IRMM) etc on behalf of Consultative Committee for Amount of Substance (CCQM), Asian Pacific Metrology Programme (APMP), European
Metrology Programme (EUORMET) or independently. Findings of these comparisons are available on their websites/reports (BIPM website: www.bipm.fr, IMEP website: www.imep.ws, PTAC Report No. 204, 1996).

\section{Conclusions}

Use of certified reference materials in calibration of equipment and validation of test methods is essential to generate precise and accurate measurements. Their use ensures traceability of measurement to national and international measurement systems, which enhance the global acceptability of test/calibration reports, industrial and agriculture products. 


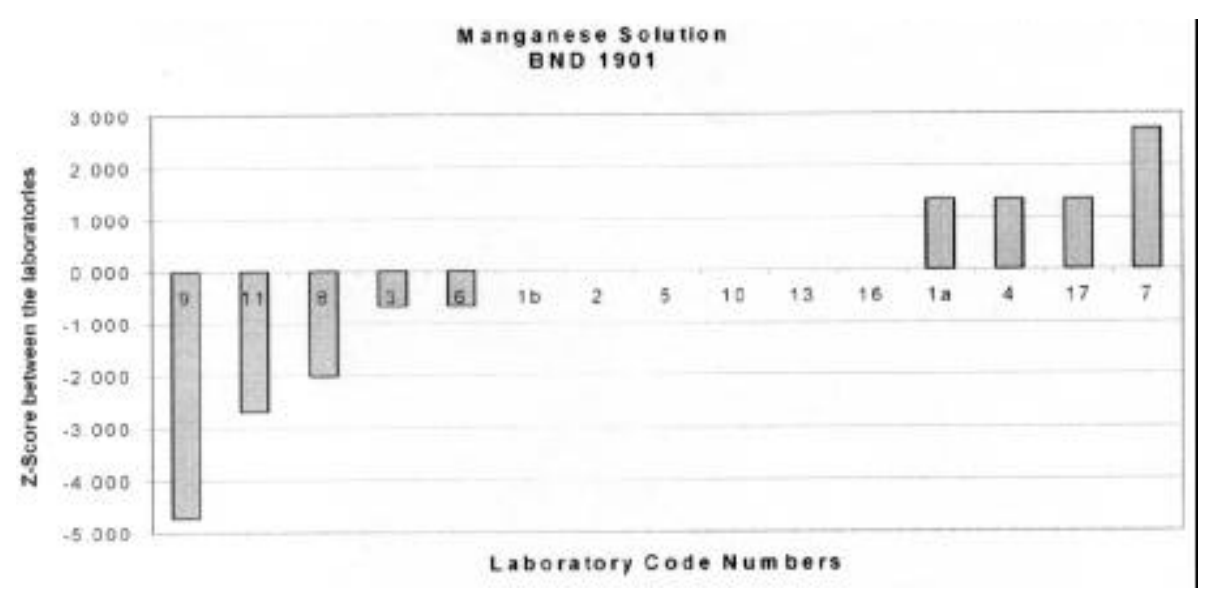

Figure 3. Z-score between the laboratories.

Table 3. Details of the CRMs of elemental solutions prepared at NPL.

\begin{tabular}{|c|c|c|c|}
\hline Sl. no. & CRM code & Elemental solution & Certified values \\
\hline \multicolumn{4}{|c|}{ Mono-elemental solutions } \\
\hline 1. & BND $101 \cdot 03$ & Lead & $1.00 \pm 0.02 \mathrm{mg} / \mathrm{L}$ \\
\hline 2. & BND 102.03 & Lead & $2.00 \pm 0.02 \mathrm{mg} / \mathrm{L}$ \\
\hline 3. & BND 201.03 & Cadmium & $1.00 \pm 0.02 \mathrm{mg} / \mathrm{L}$ \\
\hline 4. & BND $301 \cdot 02$ & Arsenic & $1.00 \pm 0.02 \mathrm{mg} / \mathrm{L}$ \\
\hline 5. & BND $401 \cdot 02$ & Chromium & $1.00 \pm 0.02 \mathrm{mg} / \mathrm{L}$ \\
\hline 6. & BND $402 \cdot 02$ & Chromium & $2 \cdot 00 \pm 0.02 \mathrm{mg} / \mathrm{L}$ \\
\hline 7. & BND $601 \cdot 02$ & Mercury & $1.00 \pm 0.02 \mathrm{mg} / \mathrm{L}$ \\
\hline 8. & BND 701.02 & Selenium & $1.00 \pm 0.02 \mathrm{mg} / \mathrm{L}$ \\
\hline 9. & BND 801.02 & Fluoride & $1.00 \pm 0.02 \mathrm{mg} / \mathrm{L}$ \\
\hline 10. & BND 1001.02 & Nickel & $1.00 \pm 0.02 \mathrm{mg} / \mathrm{L}$ \\
\hline 11. & BND 1201 & Zinc & $1.00 \pm 0.02 \mathrm{mg} / \mathrm{L}$ \\
\hline 12. & BND 1301 & Iron & $1.00 \pm 0.02 \mathrm{mg} / \mathrm{L}$ \\
\hline 13. & BND 1401 & Copper & $1.00 \pm 0.02 \mathrm{mg} / \mathrm{L}$ \\
\hline 14. & BND 901 & Nitrate & $49.94 \pm 0.48 \mathrm{mg} / \mathrm{L}$ \\
\hline 15. & BND 1801 & Calcium & $50 \cdot 24 \pm 0.42 \mathrm{mg} / \mathrm{L}$ \\
\hline 16. & BND 1901 & Manganese & $1.00 \pm 0.02 \mathrm{mg} / \mathrm{L}$ \\
\hline \multicolumn{4}{|c|}{ Multi elemental solutions } \\
\hline 17. & BND 1101.02 & $\begin{array}{l}\text { Consisting of } \\
\text { copper, iron and } \\
\text { zinc }\end{array}$ & $\begin{array}{l}99.69 \pm 0.94 \\
100.12 \pm 0.78 \text { and } \\
99.95 \pm 0.84 \mathrm{mg} / \mathrm{L}\end{array}$ \\
\hline
\end{tabular}

\section{Acknowledgements}

It is a great pleasure to acknowledge participation of the following senior scientists in the preparation of Bharatiya Nirdeshak Dravyas: Dr M Sudersanan, BARC, Mumbai; Dr A K Minocha, CBRI, Roorkee; Dr K M Appaiah, CFTRI, Mysore; Dr R S Shukla, CS \& MCRI, Bhavnagar; Dr M Vairamani, IICT, Hyderabad; Mr R K Chauhan, IIP, Dehradun; Dr A S Sarpal, R \& D Centre, IOC, Faridabad; Dr S N Singh, NBRI, Lucknow; Dr J R Behari, ITRC, Lucknow; Dr V I Pandit, NEERI, Nagpur; Dr V Balaram, NGRI, Hyderabad; Dr Sujata Kaisary, NIO, Goa; Dr K K Gupta, NML, Jamshedpur; Mr M C Nebhnani, R \& D Centre, NTPC, Noida; Dr J Murlidhar,
RRL, Bhubaneswar; Dr P Kotoky, RRL, Jorhat. The author is thankful to his colleagues Mr Prabhat K Gupta, Dr Nahar Singh, Mr R K Saxena, Mrs Abha Bhatnagar and Mrs Sunita Raina for assistance in preparation, measurements and valuable suggestions. He is also grateful to Dr Vikram Kumar, Director, NPL, for his constant encouragement and support to the programme.

\section{References}

Agrawal A K and Krishan Lal 2001 Preparation and dissemination of certified reference materials: Indian experience in advances in metrology and global trade (eds) A K Agrawal et al (New Delhi: Metrology Society of India) pp. 393-400 
Agrawal A K, Saxena R K, Abha Bhatnagar, Sunita Ganju and Krishan Lal 2003 Assessment of quality of water in environmental pollution (eds) V P Singh and R N Yadava (New Delhi: Allied Publishers) pp. 3-9

Balaram V et al 2000 Indian J. Chem. A39 567

BIPM website: www.bipm.fr

EURACHEM/CITAC Guide on Quantifying Uncertainty in Analytical Measurement 2000 Second Ed. Web: www.vtt.fi/ket/ eurachem/quam2000-p1.pdf

Guidelines for Estimation and Statement of Overall Uncertainty in Measurement Results 1996 National Accreditation Board for Testing and Calibration Laboratories, India

Gupta P K, Agrawal A K and Krishan Lal 2002 An improved apparatus useful for ultra-purification of liquids by subboil distillation and a process therefore, Indian Patent No. 187019

Gupta P K, Chetna Kaw, Sunita Ganju, Agrawal A K, Ramchandran R, Sarkar A K and Krishan Lal 1993 Fresenius J. Anal. Chem. 345278

Gupta P K, Agrawal A K, Ramchandran R, Sarkar A K and
Krishan Lal 1989 Preparation of ultra-pure water and certified aqueous solution of lead as reference materials, Proceedings ISCRM 89, China (New York: Pergamon Press) pp. 82-89

IMEP website: www.imep.ws

ISO/IEC 17025 - 1999 General Requirements for the Competence of Testing and Calibration Laboratories, International Standards Organization (ISO), Geneva

ISO Guide 351989 Certification of reference materialsGeneral and statistical principles, International Standards Organization (ISO), Geneva

ISO Guide 301992 Terms and definitions used in connection with reference materials, International Standards Organization (ISO), Geneva

Moody J R and Lindstrom R M 1977 Anal. Chem. 492264

New Statistics to NATA's Proficiency Programmes 1997 National Association of Testing Authorities, Australia

PTAC Report No. 204 on Water Proficiency Testing 1996 Subprogramme 26, National Association of Testing Authorities, Australia 